\title{
ДОЛГОСРОЧНЫЕ ТЕНДЕНЦИИ РОСТА ПРОИЗВОДСТВА ПРОДУКЦИИ ЖИВОТНОВОДСТВА С УЧЕТОМ ИЗМЕНЕНИЯ ИНСТИТУЦИОНАЛЬНОЙ СТРУКТУРЫ
}

\author{
(c) 2020 Васильченко Марианна Яковлевна \\ кандидат экономических наук, старший научный сотрудник \\ Институт аграрных проблем Российской академии наук, Россия, Саратов \\ E-mail: mari.vasil4enko@yandex.ru
}

Исследованы тенденции увеличения производства животноводческой продукции с учетом изменений институциональной структуры. Сравнение индикаторов количественного и качественного экономического роста отдельных сегментов животноводства за 2013-2018 гг. свидетельствует об изменениях институциональной среды, инновационности производства и затрат ресурсов. Выявлено воздействие инновационной государственной поддержки на динамику производственных и ресурсных показателей молочного скотоводства, сделан вывод об увеличении доли добавленной стоимости в молочнопродуктовой цепочке.

Ключевые слова: агропромышленный комплекс, институциональная структура, экономический рост, инновационный процесс, животноводство, государственная поддержка

\section{Введение}

Экономическое развитие различных секторов, в том числе и агропромышленного комплекса, характеризуется структурными изменениями в результате воздействия технологических и институциональных факторов. Существенность вышеобозначенных факторов в долгосрочном развитии обоснована теориями экономического развития и экономического роста. Достаточно распространенная теория экономического развития Й. Шумпетера связывает процесс экономического развития преимущественно с инновациями; вклад инноваций в экономический рост отражает и теория Р. Солоу. Согласно теоретическим подходам С. Кузнеца, экономический рост рассматривается как следствие развития техники и изменений в институциональной структуре [1]. Если институциональная структура обеспечивает прирост производительности и одновременно экономию ресурсов, то можно вести речь о качественном экономическом росте. Дисфункция экономических институтов, под которой можно понимать несовершенство механизмов государственной поддержки товаропроизводителей агропромышленного комплекса, препятствует долгосрочному экономическому росту.

Среди современных теорий следует отметить труды Andergassen, Fr. Nardini, M. Ricottilli), определивших технологический разрыв в качестве существенного барьера распространения инноваций и достижения экономического роста [2].
Цель: выявление долгосрочных тенденций увеличения производства животноводческой продукции для решения задачи повышения конкурентоспособности в условиях изменения институциональной структуры.

Методика исследований.

В исследовании использованы методические подходы автора к оценке инновационности производства, инновационных производственных ресурсов и инновационной поддержки животноводства.

Результаты исследования.

Структурные сдвиги в животноводческом подкомплексе России, происходящие в результате реализации соответствующих мер агропродовольственной политики, позволили выявить существенные различия в количественных и качественных параметрах экономического роста в различных институциональных секторах, причем эти изменения в наибольшей степени заметны на межотраслевом уровне.

Первая тенденция - доминирование сельскохозяйственных организаций в производстве отдельных видов продукции в результате количественного и качественного экономического роста, компенсирующего падающие объемы продукции в личных подсобных и фермерских хозяйствах в результате значительного технологического разрыва. Особенно заметен этот процесс в подотрасли свиноводства, где сформировано высокотехнологичное импортозамещающее производство. С 2013 по 2018 гг. 
производство в сельскохозяйственных организациях возросло на 60,2\%, что было связано с реализацией крупных инвестиционных проектов. В 2018 г. Министерство сельского хозяйства просубсидировало 14489 проектов, из которых $22,4 \%$ приходилась на подотрасль свиноводства и 17,9\% - птицеводства. Тенденции долгосрочного роста на протяжении последних десяти лет наблюдаются и в птицеводческой отрасли, причем приоритетным направлением развития остается формирование базы отечественных генетических ресурсов.

Положительной тенденцией является наблюдающееся с 2017 г. увеличение валового производства молока, что достигнуто вследствие увеличения объемов государственной поддержки процессов модернизации и технологического перевооружения. В 2019 г. производство молока во всех категориях хозяйств составило 31,3 млн. т, что превысило плановый индикатор Госпрограммы на 0,9\% и уровень 2018 г.- на 2,4\%. Необходимо отметить, что молочное скотоводство конкурирует за средства поддержки с другими отраслями агропромышленного комплекса. Например, в структуре субсидий по льготным инвестиционным кредитам доля молочного скотоводства в 2018 г. составила 21\%, в 2019 г.18\%. По оценкам Минсельхоза, в 2020 г. Россия сможет достигнуть уровня производства молока 31,6-32 млн. т. [3]. Подобный оптимистический сценарий может быть реализован, по нашему мнению, при условии активизации процессов модернизации и технического перевооружения. Ограниченное количество реализуемых проектов в молочном животноводстве не позволяет значительно увеличить объем и компенсировать уменьшающиеся объемы производства в остальных категориях хозяйств. Данная тенденция «ограниченного» роста в молочном скотоводстве, по нашим оценкам, сохранится и в среднесрочной перспективе.

Вторая тенденция - увеличение уровня инновационности производственного и ресурсного потенциала, о чем свидетельствуют нормированные показатели продуктивности и использования отдельных ресурсов. Сравнение индикаторов количественного и качественного экономического роста отдельных сегментов животноводства за 2013-2018 гг. свидетельствует об изменениях институциональной среды, инновационности производства и затрат ресурсов (таблица).

По данным таблицы можно сделать вывод о более высоком уровне интенсивности производ- ства мяса свиней в сельскохозяйственных организациях. Напротив, доля производства молока и мяса КРС в хозяйствах населения достаточно стабильна, хотя за последние пять лет уровень интенсивности производства в этой категории хозяйств постепенно снижается. Следует учитывать «производность» хозяйств населения от сельскохозяйственных организаций по обеспечению кормами, ветеринарному обслуживанию. Организация выращивания и откорма мясного скота, получившее распространение в ряде регионов России, предполагает участие населения и малого бизнеса в технологическом процессе. Во многом способствуют развитию мясного скотоводства меры государственной поддержки крестьянских (фермерских) хозяйств и создания семейных животноводческих ферм.

Оценка инновационности производства и затрат ресурсов с использованием предложенных индикаторов показывает заметные изменения в сторону повышения уровня инновационности для всех рассматриваемых видов продукции. Особенно заметно инновационное ресурсное замещение затрат кормов в свиноводстве, где успешно функционирует промышленный сектор, и многие комплексы уже достигли мирового уровня по затратам основных видов ресурсов.

Для выявления инновационной доминанты государственной поддержки молочного скотоводства использовались индикаторы удельного веса инновационной поддержки в общей сумме средств господдержки (масштабность поддержки) и величина инновационной поддержки в расчете на корову (интенсивность поддержки) [4]. Согласно авторской позиции, инновационная поддержка включает средства, направленные на активизацию инновационных процессов в производстве определенных видов продукции. Сравнение значений индикаторов за период 2013-2018 гг. в целом по России показало положительное влияние инновационной поддержки на динамику производственных и ресурсных показателей. При вполне сопоставимых значениях индикатора государственной поддержки в расчете на корову (10,91 тыс. руб. в 2013 г. и 10,9 тыс. руб. в 2018 г.) структура господдержки изменилась в направлении инновационной составляющей. Если в 2013 г. в расчете на корову приходилось 1,1 тыс. руб. средств инновационной поддержки, то в 2018 г.- уже 4,1 тыс. руб. Подобная ситуация объясняется расширением числа инструментов поддержки, которые можно отнести к инновационным. Начиная с 2015 г., 
Таблица 1. Индикаторы интенсивности и инновационности производства и ресурсов в животноводстве России

\begin{tabular}{|c|c|c|}
\hline Показатели & 2013 г. & 2018 г. \\
\hline \multicolumn{3}{|l|}{ Интенсивность производства животноводческой продукции } \\
\hline Производство мяса КРС на 100 га пашни в сельскохозяйственных организациях, т & 0,81 & 0,85 \\
\hline Производство мяса КРС на 100 га пашни в хозяйствах населения, т & 1,5 & 1,3 \\
\hline Производство мяса КРС на 100 га пашни в крестьянских (фермерских) хозяйствах, т & 0,16 & 0,24 \\
\hline Производство мяса свиней на 100 га пашни в сельскохозяйственных организациях, т & 2,2 & 3,5 \\
\hline Производство мяса свиней на 100 га пашни в хозяйствах населения, т & 0,88 & 0,58 \\
\hline Производство мяса свиней на 100 га пашни в крестьянских (фермерских) хозяйствах, т & 0,06 & 0,05 \\
\hline Производство молока на 100 га пашни в сельскохозяйственных организациях, т & 12,1 & 13,9 \\
\hline Производство молока на 100 га пашни в хозяйствах населения, т & 12,1 & 10,2 \\
\hline Производство молока на 100 га пашни в крестьянских (фермерских) хозяйствах, т & 1,6 & 2,1 \\
\hline Среднегодовой надой молока в сельскохозяйственных организациях, кг & 4519 & 5962 \\
\hline Среднегодовой надой молока в хозяйствах населения, кг & 3496 & 3524 \\
\hline Среднегодовой надой молока в крестьянских (фермерских) хозяйствах, кг & 3323 & 3799 \\
\hline Среднесуточный привес мяса КРС в сельскохозяйственных организациях, г & 526 & 630 \\
\hline Среднесуточный привес мяса свиней в сельскохозяйственных организациях, г & 504 & 557 \\
\hline \multicolumn{3}{|l|}{ Инновационность производства и затрат ресурсов } \\
\hline Инновационность производства молока в сельскохозяйственных организациях, \% & 53,1 & 66,2 \\
\hline Инновационность производства мяса КРС в сельскохозяйственных организациях, \% & 58,4 & 71,0 \\
\hline Инновационность производства мяса свиней в сельскохозяйственных организациях, \% & 63,0 & 70,0 \\
\hline $\begin{array}{l}\text { Инновационность затрат кормов на производство молока в сельскохозяйственных } \\
\text { организациях, \% }\end{array}$ & 60 & 70,0 \\
\hline $\begin{array}{l}\text { Инновационность затрат кормов на производство мяса КРС в сельскохозяйственных } \\
\text { организациях, \% }\end{array}$ & 67 & 80,0 \\
\hline $\begin{array}{l}\text { Инновационность затрат кормов на производства мяса свиней в сельскохозяйственных } \\
\text { организациях, \% }\end{array}$ & 87 & 90,0 \\
\hline
\end{tabular}

к субсидиям на поддержку племенного скота добавились субсидии на возмещение части затрат на создание и модернизацию объектов; с 2017 г. осуществляется льготное инвестиционное кредитование (эта мера введена как для молочного, так и мясного скотоводства, а также для растениеводства и переработки продукции). Как подтвердили результаты предыдущих исследований, структура государственной поддержки молочного скотоводства (в том числе и инновационной) имеет четко выраженную региональную специфику. Необходимо отметить также увеличение доли средств господдержки из Федерального бюджета с 62,9\% в 2013 г. до 85,3\% в 2018 г. Взаимосвязь между инновационными ресурсами господдержки и индикаторами производства молока в 2013-2018 гг. представлена на рисунке 1.

Увеличение инновационной государственной поддержки оказало воздействие на ресурсные и результативные индикаторы производства. В рассматриваемом периоде доля племенных коров в СХО, К(Ф)Х и ИП увеличилась на 6,9 процентных пункта, товарность молока в хозяйствах всех категорий - на 8,4 процентных пункта. В наибольшей степени возросло значение индикатора инновационности производства молока, который рассчитывается для сельскохозяйственных организаций.

Необходимо отметить, что российские предприятия, за исключением высокотехнологичных отраслей обрабатывающей промышленности, недостаточно вовлечены в инновационные процессы. Согласно исследованиям специалистов Высшей школы экономики за 2017 г. в животноводстве объем инновационных товаров, работ и услуг составил лишь 1,7\% от общего объема отгруженных товаров, выполненных работ и услуг, а удельный вес организаций, осуществляющих инновации - 3,9\% [5]. Установлено, что более крупные предприятия наиболее активно используют средства государственной поддержки: в 2016-2018 гг. около 72\% компаний, относящихся к высокотехнологичным отраслям, воспользовались по меньшей мере одним инструментом [6]. Среди малых предприятий 

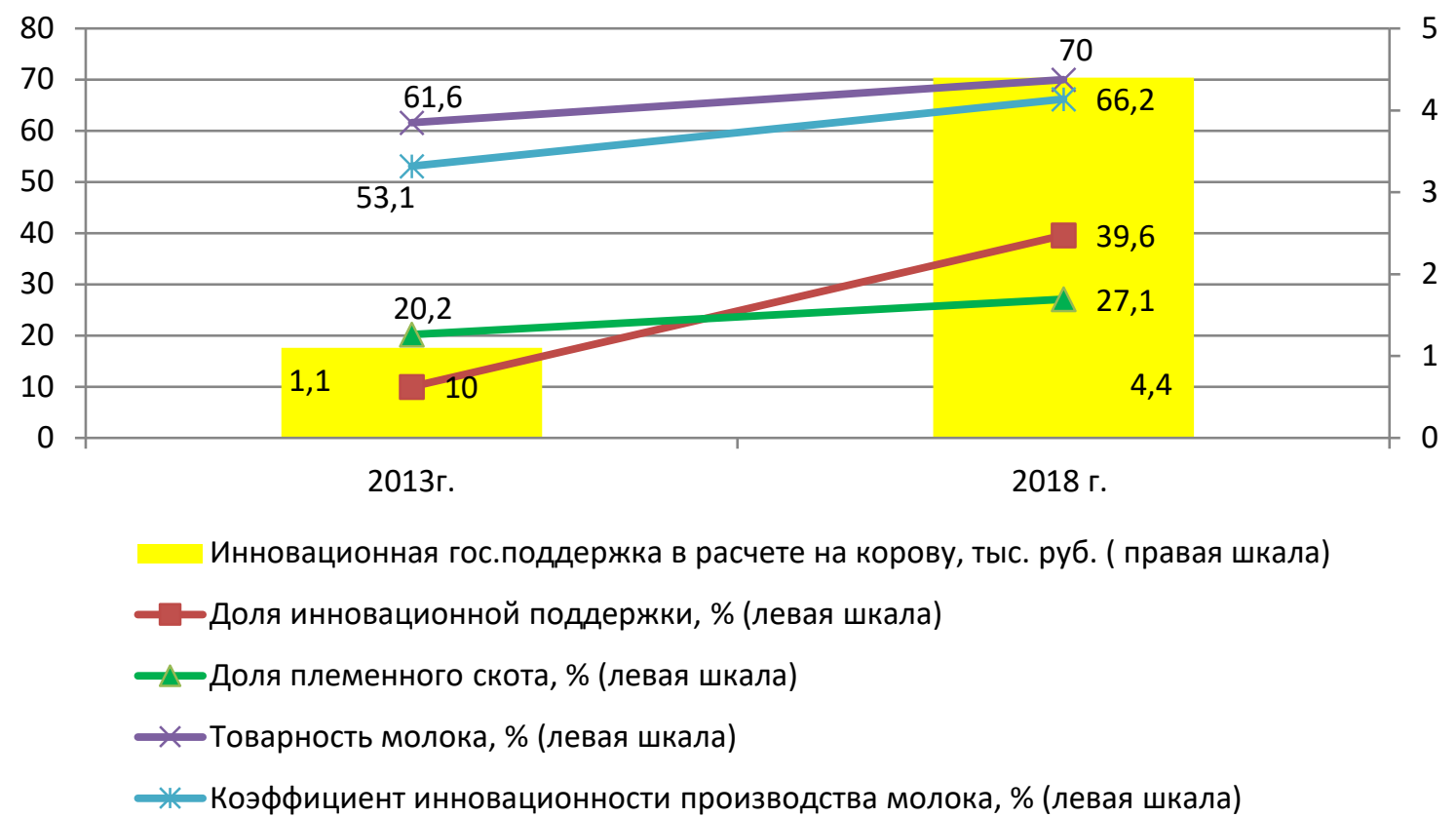

Puc. 1. Воздействие инновационной поддержки на развитие молочного скотоводства России (2013-2018 гг.)

данного сегмента экономики использовали средства поддержку лишь 42\% от общего их числа. Поэтому тенденция расширения такой меры поддержки в агропромышленном комплексе как льготное инвестиционное и краткосрочное кредитование применительно к малым формам хозяйствования будет способствовать увеличению объемов производства животноводческой продукции. Положительный эффект будет достигнут в случае предоставления из Федерального бюджета прямой поддержки приобретения техники, оборудования и технологий с высокой инновационной составляющей [7].

Следующая важная тенденция - постепенное увеличение доли добавленной стоимости в продуктовых цепочках, причем этот процесс происходит как на стадии производства, так и переработки, что позволяет повысить конкурентоспособность продукции и уровень самообеспеченности. Принимая во внимание наличие доступной информации, расчеты проводились по молочнопродуктовой цепочке. Для исследования были предложены индикаторы, характеризующие соотношение переработанного и товарного молока; соотношение продуктов с высокой долей добавленной стоимости и товарных ресурсов; глубину переработки молока. Индикатор глубины переработки рассчитывался как доля сыров, сливочного масла и сухого молока в объеме переработаной продукции.

Сопоставление индикаторов за 2015-2018 гг. позволило характеризовать наметившиеся тен- денции в развитии молочнопродуктовой цепочки (рис. 2).

В структуре переработки молока происходит постепенное увеличение молокоёмкой продукции, что в наибольшей степени заметно на примере производства сыров и сырной продукции, доля которых в товарных ресурсах молока в 2015-2018 гг. увеличилась на 7 процентных пунктов. Доля сливочного масла осталась неизменной, а сухого молока - незначительно возросла (на 0,5 процентных пункта). Комплексный индикатор глубины переработки, напротив, снизился в среднем по России на 8,1 процентных пункта, что не дает достаточно объективную картину в силу ярко выраженной региональной специфики переработки молочной продукции. Постепенное повышение уровня самообеспеченности молоком и молочными продуктами свидетельствует о более высокой доле потребления цельномолочной продукции, поэтому положительная динамика молокоёмкой продукции может быть достигнута в случае осуществления мер государственной поддержки по стимулированию спроса потребителей.

Таким образом, использование индикаторов инновационности производственных и ресурсных показателей отдельных подотраслей животноводства позволило выявить тенденции роста производства животноводческой продукции с учетом изменений институциональной структуры и оценить возможности увеличения доли добавленной стоимости в продуктовых цепочках. 


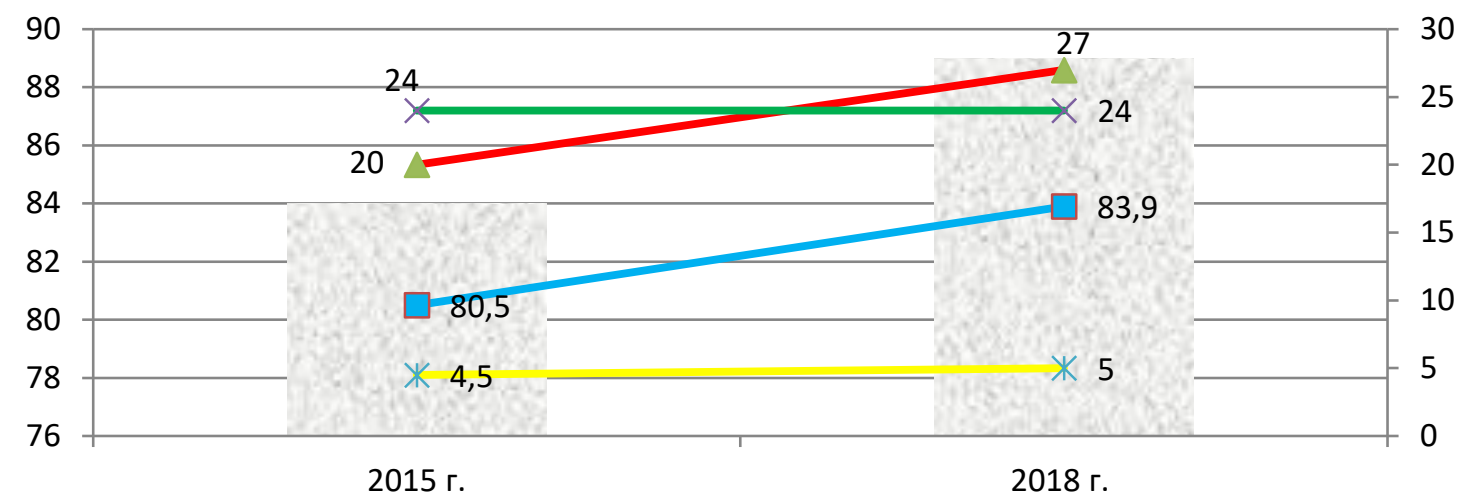

Соотношение переработанного и товарного молока, \% (левая шкала)

- Самообеспеченность по молоку и молочным продуктам, \% (левая шкала)

- Уд. вес сыров в товарных ресурсах, \% (правая шкала)

×Удельный вес сливочного масла в товарных ресурсах, \% (правая шкала)

* Удельный вес сухого молока в товарных ресурсах, \% ( правая шкала)

Puc. 2. Индикаторы цепочки создания добавленной стоимости молока в России

\section{Библиографический список}

1. Кузнеи, С. Современный экономический рост: результаты исследований и размышления: Нобелевская лекция // Нобелевские лауреаты по экономики: взгляд из России.-Спб.«Гууманистика», 2003.- С. 104.

2. Andergassen R; Nardini Fr; Ricottill, M. Innovation diffusion, general purpose technologies and economic growth // STRUCTURAL CHANGE AND ECONOMIC DYNAMICS. 2017. - Vol. 40. - P. 72-80.

3. Производство молока во всех категориях хозяйств увеличилось на 5,8\%.- Режим доступа: http://mcx.ru/ press-service/news/proizvodstvo-moloka-vo-vsekh-kategoriyakh-khozyaystv-uvelichilos-na-5-8/.

4. Васильченко М.Я. Инструменты поддержки процесса распространения инноваций в отраслях АПКк (на примере молочного скотоводства) // Региональные агросистемы: экономика и социология. 2019. № 3.- Режим доступа: https://elibrary.ru/item.asp?id=385974303/

5. Индикаторы инновационной деятельности: 2019: статистический сборник / Л.М. Гохберг, К.А. Дитковский, И.А. Кузнецова и др.; Нац. исслед. ун-т «Высшая школа экономики».- М.: НИУ ВШЭ, 2019. - 376 с. - Режим доступа: https://www.hse.ru/primarydata/ii2019.

6. Спрос на инструменты государственной инновационной политики со стороны предприятий высокотехнологичных отраслей: НИУ ВШЭ, 2019. - Режим доступа: https://docviewer.yandex.ru/view/130929660.

7. Суровцев В., Никулина Ю., Паюрова Е. Достижение пороговых показателей доктрины продовольственной безопасности по молоку: прогноз, факторы и риски // АПК: экономика, управление.- 2019. № 12.- С. 38 50. 